\title{
Serum Calcium Levels in Preterm and Term Neonates on Phototherapy
}

\author{
Arora $\mathbf{S}^{1}$, Narang $\mathrm{GS}^{2}$, Singh $\mathbf{G}^{3}$
}

\begin{abstract}
Introduction: In addition to known causes of hypocalcemia like, prematurity, Intrauterine growth retardation (IUGR), asphyxia, sepsis, infants of diabetic mothers (IDM), high phosphate formula, Magnesium deficiency, effect of phototherapy on serum calcium levels has caught attention of researchers from time to time. The objectives of this study were to evaluate serum calcium levels in relation to duration of phototherapy, single surface Vs double surface phototherapy in term and preterm neonates. Materials and Methods: This study was done in a neonatal ICU of a tertiary care hospital. Hundred preterm and term neonates $>72 \mathrm{hrs}$ of age with weight appropriate for gestational age were selected. Serum calcium levels were measured at the onset and after $24 \mathrm{hrs}$ and $48 \mathrm{hrs}$ of phototherapy and results were analyzed in both the groups. Results: Hypocalcemia was more frequently observed in term group as compared to preterm group. Hypocalcemia occurred more frequently after $48 \mathrm{hrs}$ of continuous phototherapy in both groups. Hypocalcemia was more common under DSPT as compared to SSPT in both groups. Conclusion: Hypocalcemia is a significant problem in neonates subjected to phototherapy.
\end{abstract}

Key words: Hyperbilirubinemia, Hypocalcemia, single surface phototherapy, double surface phototherapy, serum bilirubin.

\section{Introduction}

$\mathrm{P}$ athological hyperbilirubinemia with its neurotoxic complications is one of the reasons for admission of newborns to neonatal unit in addition to sepsis, perinatal asphyxia, prematurity, respiratory distress syndrome and metabolic derangements ${ }^{1}$. Phototherapy is a convenient and inexpensive modality for the treatment of neonatal hyperbilirubinemia which has revolutionized the management of jaundice thereby decreasing the number of exchange transfusions drastically ${ }^{2}$. It requires protection of eyes to prevent retinal damage, covering genitalia to prevent chromatid changes, maintenance of adequate hydration particularly in preterm babies due to large surface area and euthermia. Decreased activity of glutathione reductase in red blood cells and subsequent haemolysis and preventive role of vitamin $B_{2}$ was suggested by WuZL ${ }^{3}$. Green stools due to transient lactose intolerance and increased concentration of bile salts and unconjugated bilirubin in the bowel is common under phototherapy ${ }^{4}$.
'Dr. Sunita Arora, MBBS.MD, Associate Professor, ${ }^{2}$ Dr.Gursharn Singh Narang, MBBS. MD, Professor, ${ }^{3}$ Dr. Gagandeep Singh, MBBS, MD Resident. All from the Department of Paediatrics, Sri Guru Ram Das Institute of Medical Sciences and Research, Sri Amritsar, Amritsar, India.

\section{Address for correspondence}

Dr. Sunita Arora, Associate Professor

Department of Paediatrics

Sri Guru Ram Das Institute of Medical Sciences and Research

Sri Amritsar, Amritsar, India

Tel: +91-9814710274

E-mail: dr.sunita1@yahoo.com

\section{How to cite}

Hamid R, Wani Sajad, Shera AH, Sheikh Khurshid, Bhat NA, Baba AA. Meckel's Diverticulum with Multiple Ileal Ulcers as a Source of Massive Gastrointestinal Haemorrhage in a Three Year Old Child. J Nepal Paediatr Soc 2014;34(1):24-28.

doi: http://dx.doi.org/10.3126/jnps.v34i1.9165

This work is licensed under a Creative Commons Attribution 3.0 License.

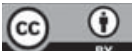

Hypocalcemia defined as total serum calcium level less than $8 \mathrm{mg} / \mathrm{dl}$ in term and less than $7 \mathrm{mg} / \mathrm{dl}$ in preterm babies is an important metabolic aberration in neonatal period due to its ill effects on neurological and cardiac functions ${ }^{5}$. Hypocalcemia may be asymptomatic particularly early onset hypocalcemia or symptomatic in the form of jitteriness, lethargy, apnea, hypotonia, high pitched cry, stridor, irritability and seizures. Uninhibited effect of corticosteroids due to decreased synthesis of melatonin from pineal gland under phototherapy is thought to be responsible for hypocalcemia. 
Blue lamps with a peak output of $425-475 \mathrm{~nm}$ at a distance of $18^{\prime \prime}(45 \mathrm{~cm})$ with irradiance of $6-12 \mu \mathrm{w} / \mathrm{cm}^{2} /$ $\mathrm{nm}$ constitutes conventional phototherapy whereas intensive phototherapy involves increasing irradiance to more than $25 \mu \mathrm{w} / \mathrm{cm}^{2} / \mathrm{nm}^{6,7}$.

Because of widespread use of phototherapy for treatment of neonatal hyperbilirubinemia, present study was conducted to study the effect of phototherapy, its duration and single (SSPT) versus (vs) double surface phototherapy (DSPT) on serum calcium levels in term and preterm babies and its clinical implications if any.

\section{Materials and Methods}

Study comprised of 100 inborn and out born newborns admitted in NICU of Sri Guru Ram Das Institute of Medical Sciences and Research for treatment of hyperbilirubinemia. 46 were preterms and 54 were term babies. They were subjected to single or double surface phototherapy depending upon serum bilirubin values. Phototherapy was given according to the American Academy of Pediatrics Subcommittee on hyperbilirubinemia guidelines in neonates 35 or more weeks of gestation ${ }^{8}$. In neonates $<35$ weeks gestation phototherapy was started when total serum bilirubin was $0.75 \%$ of birth weight in grams. Cut off values were $7-9 \mathrm{mg} / \mathrm{dl}$ in $1000-1500$ grams, $10-12 \mathrm{mg} / \mathrm{dl}$ in $1500-2000$ grams, $13-15 \mathrm{mg} /$ dl in 2000-2500 grams birth weight ${ }^{9}$. Single surface phototherapy was used for serum bilirubin level in the range $50-60 \%$ and double surface phototherapy for serum bilirubin level in the range of $60-70 \%$ of recommended value for exchange transfusion for different birth weights ${ }^{10}$. Babies with IUGR, IDM, prolonged and difficult labor, respiratory distress and those receiving cow's milk were excluded from study. Phototherapy units with four blue and two white lights with a wavelength of $420-480 \mathrm{~nm}$ and irradiance of $6-12 \mu \mathrm{w} / \mathrm{cm}^{2} / \mathrm{nm}$ were used placed at a distance of $45 \mathrm{~cm}$ from skin surface. Serum calcium was measured at the onset and then at 24 and $48 \mathrm{hrs}$ of phototherapy by OCPC method. In addition to CBC and blood group, serum bilirubin was estimated by Jendrassik and Grof method. Data was compiled and statistically analyzed with student's $t$ test. $t$ value was calculated and compared with table value for given degree of freedom and level of significance calculated for $95 \%$ confidence limit.

$T={ }^{-} d(n) \frac{1}{2} S=\left[\sum d^{2} \cdot-n\left(d^{-}\right)^{2} /(n-1)\right]^{1 / 2}{ }^{-} d=\Sigma d / n$ and interpreted following $\mathrm{t}$ table.

\section{Results}

All the 46 preterms and 54 term babies were appropriate for gestational age and more than $72 \mathrm{hrs}$ of age. Majority of babies (preterm 78\% and term 85\%) were 72-96 hrs old at the initiation of phototherapy. Gestational age was 34-37 weeks in 28 preterms and $30-34$ weeks in 18 preterm babies thus all were more than 30 weeks of gestation. Hypocalcemia was observed in 20 out of 46 preterms (43\%) and 30 out of 54 term neonates (56\%) after $48 \mathrm{hrs}$ of continuous phototherapy.

At the end of $24 \mathrm{hrs}$ four preterms (9\%) developed hypocalcemia with number increasing to $20(43 \%)$ at end of $48 \mathrm{hrs}$ with a t value 9.786 and 11.443 respectively which is more than table value of $t$ at $95 \%$ confidence level (t $0.05=2.000$ ) which was statistically significant. 23 term babies (42\%) developed hypocalcemia at the end of $24 \mathrm{hrs}$ and number rose to $30(56 \%)$ at the end of $48 \mathrm{hrs}$ when three babies had serum calcium levels less than $7 \mathrm{mg} / \mathrm{dl}$. t value was 7.58 and 9.66 respectively which was statistically significant (Table 1 ).

Out of 24 preterms subjected to SSPT, none had hypocalcemia at end of $24 \mathrm{hrs}$ while seven had hypocalcemia at the end of $48 \mathrm{hrs}$. $\mathrm{t}$ value was more than table value of $t$ at $95 \%$ confidence level ( $t 0.05=$ 2.069). On the other hand under DSPT four preterms (18\%) out of 22 had hypocalcemia at the end of $24 \mathrm{hrs}$ and 13 (59\%) had serum calcium level below $7 \mathrm{mg} / \mathrm{dl}$ at $48 \mathrm{hrs}$, $\mathrm{t}$ value higher than table value of $\mathrm{t}$ at $95 \%$ confidence level which is statistically significant (Table 2).

11 (33\%) and 14 (42\%) term babies developed hypocalcemia under SSPT at 24 and $48 \mathrm{hrs}$ respectively. Fall in serum calcium level is statistically significant as $t$ value is more than table value of $t$ at $95 \%$ confidence level (t 0.05=2.02). Under DSPT 12 (57\%) term babies had hypocalcemia at $24 \mathrm{hrs}$ and 16 (76\%) term babies developed hypocalcemia at $48 \mathrm{hrs}$. Two term neonates had serum calcium level below $7 \mathrm{mg} / \mathrm{dl}$ at $48 \mathrm{hrs}$. Fall in serum calcium level is statistically significant since $t$ value is more than table value of $t$ at $95 \%$ confidence level (t. $0.05=2.084$ ) (Table 3).

On the whole, hypocalcemia occurred more commonly under DSPT than SSPT in both term and preterm babies. It was more frequently encountered in term as compared to preterm babies 14 (42\%) vs 7 (29\%) under SSPT and 16 (76\%) vs 13 (59\%) under DSPT (Table 4). 
Symptomatic hypocalcemia was more common in preterm group than term group. Jitteriness was the commonest symptoms observed in 7 (35\%) preterms and $3(10 \%)$ term babies followed by lethargy in 2
(10\%) preterms and 1 (4\%) term baby. Symptoms like irritability, poor feeding and convulsions were not encountered in the present study (Table 5).

Table 1: Serum calcium levels after $24 \mathrm{hrs}$ and $48 \mathrm{hrs}$ of phototherapy

\begin{tabular}{|c|c|c|c|c|c|c|}
\hline \multicolumn{9}{|c|}{ Preterm (n=46) } & \multicolumn{3}{c|}{ Term (n=54) } \\
\hline Serum Calcium $\mathbf{~ m g / d l ~}$ & $\mathbf{0 ~ h r s}$ & $\mathbf{2 4} \mathbf{~ h r s}$ & $\mathbf{4 8} \mathbf{h r s}$ & $\mathbf{0 ~ h r s}$ & $\mathbf{2 4 h r s}$ & $\mathbf{4 8 h r s}$ \\
\hline$<7$ & -- & $4(9)$ & $20(43)$ & $-(-)$ & $-(-)$ & $3(6)$ \\
\hline $7.1-8$ & $10(22)$ & $21(46)$ & $19(41)$ & $-(-)$ & $23(42)$ & $27(50)$ \\
\hline $8.1-9$ & $22(48)$ & $20(43)$ & $7(15)$ & $39(72)$ & $29(54)$ & $24(44)$ \\
\hline$>9$ & $14(30)$ & $1(2)$ & $-(-)$ & $15(28)$ & $2(4)$ & $(-)$ \\
\hline t value & & 9.786 & 11.443 & 7.58 & 9.66 & \\
\hline
\end{tabular}

Figures in paranthesis indicate percentage

Table 2: Effect of SSPT Vs DSPT on serum calcium level in preterm babies.

\begin{tabular}{|c|c|c|c|c|c|c|}
\hline \multicolumn{9}{|c}{ SSPT $(\mathbf{n = 2 4 )}$} & \multicolumn{3}{c|}{ DSPT( $\mathbf{n = 2 2})$} \\
\hline Serum Calcium levels mg/dl & $\mathbf{0} \mathbf{~ h r s}$ & $\mathbf{2 4} \mathbf{h r s}$ & $\mathbf{4 8 h r s}$ & $\mathbf{0} \mathbf{h r s}$ & $\mathbf{2 4} \mathbf{h r s}$ & $\mathbf{4 8} \mathbf{h r s}$ \\
\hline$<7$ & -- & -- & $7(29)$ & -- & $4(18)$ & $13(59)$ \\
\hline $7.1-8$ & $3(13)$ & $11(46)$ & $13(54)$ & $7(32)$ & $10(46)$ & $6(27)$ \\
\hline $8.1-9$ & $13(54)$ & $12(50)$ & $4(17)$ & $9(41)$ & $8(36)$ & $3(14)$ \\
\hline$>9$ & $8(33)$ & $1(4)$ & - & $6(27)$ & - & - \\
\hline t. value & & 5.856 & 7.65 & & 8.895 & 9.02 \\
\hline
\end{tabular}

Figures in paranthesis indicate percentage

Table 3: Effect of SSPT vs DSPT on serum calcium level in term babies.

\begin{tabular}{|c|c|c|c|c|c|c|}
\hline \multicolumn{9}{|c|}{ SSPT $(\mathbf{n = 3 3})$} & \multicolumn{3}{c|}{ DSPT (n=21) } \\
\hline Serum Calcium levels $\mathbf{~ m g / d l}$ & $\mathbf{0} \mathbf{h r s}$ & $\mathbf{2 4} \mathbf{h r s}$ & $\mathbf{4 8 h r s}$ & $\mathbf{0}$ hrs & $\mathbf{2 4} \mathbf{h r s}$ & $\mathbf{4 8} \mathbf{h r s}$ \\
\hline$<7$ & -- & -- & $1(3)$ & -- & - & $2(9)$ \\
\hline $7.1-8$ & - & $11(33)$ & $13(39)$ & & $12(57)$ & $14(67)$ \\
\hline $8.1-9$ & $23(70)$ & $20(61)$ & $19(58)$ & $16(76)$ & $9(43)$ & $5(24)$ \\
\hline$>9$ & $10(30)$ & $2(6)$ & - & $5(24)$ & & - \\
\hline t. valve & & 5.3112 & 6.685 & & 5.836 & 7.28 \\
\hline
\end{tabular}

Figures in paranthesis indicate percentage

Table 4: Comparison of hypocalcemia in Preterm \& term neonates under SSPT and DSPT.

\begin{tabular}{|l|c|c|c|c|c|}
\hline & Total number & Number on SSPT & Hypocalcemic & Number on DSPT & Hypocalcemic \\
\hline Preterm & 46 & 24 & $7(29 \%)$ & 22 & $13(59 \%)$ \\
\hline Term & 54 & 33 & $14(42 \%)$ & 21 & $16(76 \%)$ \\
\hline
\end{tabular}

Figures in paranthesis indicate percentage

Table 5: Signs and symptoms of hypocalcemia.

\begin{tabular}{|l|c|c|}
\hline & Preterm $(n=20)$ & Term $(n=30)$ \\
\hline Lethargy & $2(10 \%)$ & $1(4 \%)$ \\
\hline Irritability & -- & -- \\
\hline Poor feeding & -- & -- \\
\hline Jitteriness & $7(35 \%)$ & $3(10 \%)$ \\
\hline Convulsions & -- & \\
\hline
\end{tabular}

Figures in paranthesis indicate percentage 


\section{Discussion}

Forty six preterm $>30$ weeks of gestation and 54 term babies were enrolled for the present study. All the babies were more than 72 hrs of life to avoid effect of early onset hypocalcemia. Sethi et al $(1993)^{12}$ and Eghbalian F et al (2002) ${ }^{14}$ excluded newborns with icterus in first $24 \mathrm{hrs}$ of life. Sethi et al (1993) ${ }^{12}$ and Karamifer $\mathrm{H}$ et al $(2002)^{13}$ selected preterms more than 31 weeks whereas Eghbalian et al $(2002)^{14}$ included only term neonates.

All the term and preterm neonates in the present study were appropriate for gestational age. Same was the case in the studies done by Romagnoli et al (1979) ${ }^{16}$, Sethi el al (1993) ${ }^{12}$ and Jain BK et al (1998) ${ }^{15}$.

Hypocalcemia was more commonly encountered in term neonates 30 (56\%) as compared to preterm neonates 20 (43\%). Hypocalcemia was related to duration of phototherapy in both groups. It was detected in 4 (9\%) and 20 (44\%) preterm babies at 24 hrs and $48 \mathrm{hrs}$ of phototherapy respectively. In term group hypocalcemia was detected in 23 (42\%) and $30(56 \%)$ babies at the end of $24 \mathrm{hrs}$ and $48 \mathrm{hrs}$ of phototherapy respectively. Hypocalcemia was more commonly observed under DSPT as compared to SSPT in both groups. In preterm group, hypocalcemia occurred in 13 (59\%) neonates under DSPT as compared to 7 (29\%) under SSPT. In term group, hypocalcemia occurred in 16 (76\%) newborns under DSPT. versus 14 (42\%) under SSPT. Higher incidence of hypocalcemia in term group was probably attributed to higher cut off value of serum calcium level of $8 \mathrm{mg} / \mathrm{dl}$ as compared to $7 \mathrm{mg} / \mathrm{dl}$ in preterm babies.

Much higher incidence of hypocalcemia was observed by Sethi et $\mathrm{al}^{12}$ and lowest incidence was reported by Karamifer $\mathrm{H}$ et $\mathrm{al}^{13}$. Hypocalcemia was reported more frequently in preterm babies as compared to term babies, percentage being 90\%, 55\% and $22.6 \%$ in preterm group \& $75 \%, 30 \%$ and $87 \%$ in term group by Sethi et al (1993) ${ }^{12}$ Jain BK et al (1998) Karamifer $\mathrm{H}$ et al (2002) ${ }^{13}$. Romagnoli et al (1979) ${ }^{16}$ only studied preterm group and observed hypocalcemia in $52.3 \%$ babies.

The differential effect of single versus double surface phototherapy has not been studied by other workers. In present study symptomatic hypocalcemia was observed more frequently under DSPT as out of seven preterm having jitteriness six were under DSPT and two preterms had lethargy that too under DSPT. Jain BK et $\mathrm{al}^{15}$ and Sethi et $\mathrm{al}^{12}$ reported higher incidence of symptomatic hypocalcemia in preterm group (55\% and
$50 \%$ respectively) as compared to term group ( $30 \%$ and $15 \%$ respecively). Symptomatic hypocalcemia has not been reported by Karamifer $\mathrm{H}$ et al $(2002)^{13}$. Jitteriness was observed in $90 \%$ and $64 \%$ and irritability in $40 \%$ and $27 \%$ by Sethi et al ${ }^{12}$ and Jain BK et al ${ }^{15}$ respectively in preterm group. In term neonates jitteriness was observed in all babies by Sethi et al $^{12}$ followed by irritability in $33 \%$. Jitteriness, lethargy \& irritability was noticed in $50 \%, 33 \%$ and $50 \%$ of hypocalcemic term babies by Jain BK et al. ${ }^{15}$ In present study symptoms occurred only in term neonates under DSPT.

\section{Conclusion}

Thus hypocalcemia is a significant problem in neonates subjected to phototherapy which is a commonly used modality of treatment for neonatal hyperbilirubinemia hence there is need for closed monitoring of serum calcium levels and prophylactic calcium supplementation in neonates subjected to phototherapy.

Acknowledgements: We express our gratitude to staff and residents of NICU SGRD, who helped us in conducting the study.

Funding: None

Conflict of Interest: None

Permission from IRB: Yes

\section{References}

1. Kliegman RM, Behrman RE, Nelson WE, Jenson HB, Stanton BF; Nelson Textbook of paediatrics W.B Saunders company, $18^{\text {th }}$ edition 2008; 756-6.

2. Tan KL. Phototherapy for neonatal jaundice. Clin Perinatol 1991; 18: 423-39.

3. Wu Zl, Chen FX, Lai YH. Mechanism and prevention of hemolysis in jaundiced infants in phototherapy. Chung Hua I Hsueh Tsa Chih 1994; 74: 364-6, 3912.

4. Meharban Singh. Care of the newborn Sagar Publications, $6^{\text {th }}$ edn. 2004; 253-4.

5. Avery GB, Pathophysiology and management of the newborn Lippincott Williams and Wilkins, fifth edition 1999;722-3.

6. Dennery PA, Seidman DS, Stevenson DK. Neonatal hyperbilirubinemia. N Eng J Med 2001; 344:581-0.

7. Tan KL. The nature of dose response relationship of phototherapy for neonatal hyperbilirubinemia. J Pediatr 1977;90:448-52

8. American academy of Pediatrics Subcommittee on Hyperbilirubinemia. Management of 
hyperbilirubinemia in the newborn infant 35 or more weeks of gestation. Pediatrics 2004;114:297316.

9. Cloherty JP, Eichenwald EC, Stark AR. Manual of neonatal care 2007.Lippincot Williams and Wilkins $6^{\text {th }}$ edition; chapter 18

10. Kliegman M. The fetus and the neonatal infant. In: Behrman R, Nelson Textbook of paediatrics, $16^{\text {th }}$ edn, Philadelphia, Saunders 2000; 513-9.

11. Robertson's textbook of neonatology, chapter 35 metabolic disease part -2 endocrine disorders. Churchill Livingstone company edited by Janet MR. $4^{\text {th }}$ edition 2005; 882-3.
12. Sethi H, Saili A, Dutta AK. Phototherapy induced hypocalcaemia. Indian Pediatr 1993;30:1403-6

13. Karamifar H, Pishva N, Amirhakimi GH. Prevalence of phototherapy- induced Hypocalcemia Iran. J Med Sci 2002;27(4):166-8.

14. Eghbalian F, Monsef A. Phototherapy induced Hypocalcaemia Iran. J Med Sci 2002;27(4):169-71.

15. Jain BK, Singh H, Singh D, Toor NS. Phototherapy induced Hypocalcaemia. Indian Pediatr 1998;35(6):566-7.

16. Romagnoli C, Polidori G, Cataldi L, Tortorolo G, Segni G. Phototherapy induced Hypocalcaemia Iran. J Med Sci 2002;27(4):166-8. 